\title{
Prevalence of Extended Spectrum of Beta Lactamase (ESBL) Producing Uropathogens from Pregnant Women in a Tertiary Care Hospital
}

\author{
Sudhir Joshilkar and Madhumati Patil ${ }^{*}$ \\ Department of Microbiology, KAHER, Jawaharlal Nehru Medical College, \\ Belagavi, Karnataka, India \\ *Corresponding author
}

\section{Keywords}

Urinary tract infection, Extended Spectrum Beta Lactamase, Uropathogens

Article Info

Accepted:

xx October 2019

Available Online:

xx November 2019
Urinary tract infection (UTI) represents the most common bacterial infection in pregnancy. Urinary tract infection poses a serious health threat because of the antibiotic resistance and high recurrence rate. Extended Spectrum BetaLactamases (ESBLs) producing Enterobacteriaceae are among the most problematic multidrug resistant bacteria worldwide and are increasingly causing urinary tract infection both in hospitalized patients and outpatients making infections difficult to treat. This study was undertaken to identify the changing etiological trends of urinary tract infections (UTI), detect the prevalence of ESBL producing Uropathogens and study their antibiotic resistance profile. Urinary isolates from symptomatic UTI cases were identified by conventional methods. Antimicrobial susceptibility testing was done by Kirby Bauer's disc diffusion method. Isolates resistant to cephotaxime were tested for ESBL production by double disc synergy test method. Total 6 ESBL producing organisms were isolated out of 54-gram negative bacilli among 170 urine samples of pregnant women. The most predominant ESBL producing isolates were Escherichia coli (37.5\%), followed by Citrobacter frundii (25.0\%) and Klebsiella pneumoniae (12.5\%). The antibiogram pattern of ESBL producing isolates showed maximum sensitivity to Imipenem (75.0\%), Meropenem (75.0\%) and Gentamicin (62.5\%). This study shows that the Prevalence rate of ESBL producing E. coli and Citrobacter freundii is high in pregnant women. Most of the ESBL producing isolates were multidrug resistant. Careful detection of ESBL production and antimicrobial susceptibility testing are necessary to avoid treatment failure in patients with UTI.

\section{Introduction}

Pregnancy causes several changes in the woman's body that boost the probability of urinary tract infections (UTIs). It's been considered a frequent health problem among pregnant women, occurring within $2-10 \%$ of all pregnancies. ${ }^{1}$ If not properly treated, 
asymptomatic bacteriuria can lead to acute pyelonephritis in $30 \%$ of pregnant women and increase the risk for severe complication such as early delivery, hypertension, pre-eclampsia, low birth weight and postpartum endometritis. $^{2,3}$

Pathogens of urinary tract include Gramnegative bacilli such as E. coli, Klebsiella spp. Proteus spp. and Pseudomonas spp. and Gram-Positive cocci such as Staphylococcus and Enterococcus spp. ${ }^{4}$ Extended-spectrum beta lactamases (ESBL) are a cluster of plasmid-mediated, diverse, complex and swiftly growing enzymes that are exaggerating a chief therapeutic challenge in the treatment of hospitalized and community-based patients.

The ESBL producers often also have resistance determinants to other antibiotic groups, leaving an extremely limited range of effective antibiotic agents. ${ }^{5} \mathrm{~A}$ delay in appropriate therapy can cause severe complications.

Detection of ESBL producers from sample such as urine may be of utmost important as there is a rapid increase of resistance to broad spectrum beta lactams among uropathogens which has recently become a major health problem globally.

It leads to antibiotic ineffectiveness, increased severity of illness and cost of treatment. ${ }^{6}$ The increase in the prevalence of ESBL's worldwide creates a need for effective and easy to perform screening methods for detection. $^{7}$

This study was undertaken to identify the changing etiological trends of urinary tract infections (UTI), to detect the prevalence of ESBL producing uropathogens and to study their antibiotic resistance profile of those bacteria.

\section{Materials and Methods}

The study was carried out in the Department of Microbiology, at tertiary care hospital, Belagavi from January 2016 to December 2016. The study protocol was approved by the Institutional Ethical Committee. In the present study, 170 non-repetitive, midstream urine sample were collected in the sterile container. The samples were processed within $1 \mathrm{~h}$ of collection and were subjected for macroscopic and microscopic examination.

Further the sample is cultured on Blood agar and MacConkey agar by Standard loop technique. The culture plates were incubated at $37^{\circ} \mathrm{C}$ for $18-24 \mathrm{~h}$ under aerobic conditions. Identification of bacterial growth was confirmed by standard microbiological and biochemical techniques. ${ }^{8}$

Antibiotic sensitivity testing (AST) was performed by the Kirby-Bauer disc-diffusion method on Mueller-Hinton agar. ${ }^{9}$ The following antibiotics were tested: Gentamycin (10 mcg), Ampicillin (10 mcg), Amoxyclav (30mcg), Co-trimoxazole (25mcg), Norfloxacin (10 mcg), Nitrofurantoin (300 $\mathrm{mcg}$ ), Ceftazidime (30 $\mathrm{mcg})$, Cefuroxime (30mcg), Piperacillin-Tazobactum (100/10 $\mathrm{mcg})$, Imipenem (10 mcg) and meropenem (10 mcg). The selection of antibiotics and interpretation of inhibition zone sizes was done according to Clinical Laboratory Standards Institute-2017 guidelines. ${ }^{10}$

Phenotypic confirmatory of ESBL production was done by double-disc synergy test (DDST). Ceftazidime $(30 \mu)$ and Ceftazidime/clavulanic acid $(30 / 10 \mu \mathrm{g})$ disc (Hi Media) were placed on the Mueller Hinton agar and incubated $37^{\circ}$ C for 18-24 hrs. An increase in the zone diameter by greater than or equal to $5 \mathrm{~mm}$ around the Ceftazidime/ Clavulinic acid disk over the Ceftazidime disk alone confirmed as ESBL producers. ${ }^{10}$ Escherichia coli 25922 and 
a known in house ESBL producer were used as negative and positive controls respectively.

\section{Statistical analysis}

Data is analyzed using $\mathrm{R}$ i386 3.6.0 statistical software and Excel. Continuous variables are represented by mean \pm SD form and categorical variables by a frequency table. In below table p-value less than 0.05 indicates the significance of that variable.

\section{Results and Discussion}

The prevalence of UTI among the pregnant women was found to be $36.5 \%$ (62/170). Among total 62 isolates, 8 were Gram-positive cocci of which 2 were Staphylococcus aureus and 6 were Enterococcus species.

The ESBL and non-ESBL subjects (Patients) are more in age less than 20 years. There was no significant difference in the mean age between ESBL and non ESBL subjects as determined by t-test.

Gravidity is made into two categories as primigravida and multigravida. Gravidity and infection were independent by Chi-square test. However, odds ratio was 3.97 (CI: 3.77-4.17), that is, odds of having non-ESBL infection is 3.97 times more for the multigravida subjects compared to primigravida subjects (Table 1).

Parity is also made into two categories, primiparous and multiparous. Parity and infections are independent by Chi-square test. However, odds (2.91, CI: 2.77-3.065) of having non-ESBL infection is 2.91 times more for the multiparous subjects compared to primiparous subjects.

There is no significant difference in the gestational age for ESBL and non-ESBL subjects by t-test (Table 1).
Among 54 gram negative bacilli, E. coli $31(50 \%)$ was the predominant one followed by $K$. pneumonia $11(17.7 \%)$. ESBL producing phenotype was found most frequently among Escherichia coli 3(9.68\%), followed by Citrobacter freundii 2(50\%), Klebsiella pneumonia 1(12.5\%), Citrobacter koseri 1(50\%), Proteus mirabilis 1(20\%) [Table 2].

\section{Antibiotics resistance outcome on $E S B L$}

The antibiotic resistance profile of ESBL bacteria, $77.78 \%$ resistance is observed for Cefuroxime antibiotic, followed by $62.5 \%$ for Trimethoprim-sulfamethoxazole and Gentamycin. A low degree of resistance to Meropenem (12.5\%) and Imipenem (14.6\%) was observed for ESBL producers and hence may be helpful in combating severe infections. Escherichia coli showed higher resistance to most of the antibiotics.

The prevalence of UTI in pregnant women was found to be $36.5 \%$. The Gram-negative bacteria predominated, with $E$. coli being the most common pathogen $(50 \%)$ isolated in the study. Prevalence of ESBL production in Enterobactericea in the present study is $14.8 \%$. Imipenem and Meropenem were found to be the most effective drug in this study, indicating that Carbapenemes are the drugs of choice for treating serious infections caused by ESBL - producing bacteria. ${ }^{12}$ Non-ESBL majority of the organism showed resistance for Amoxicillin-clavulanic acid and Ampicillin.

The ESBL producers also have resistance to other antibiotic groups and there are very few antibiotics which are effective against these agents. A delay in appropriate therapy can cause severe complications. The susceptibility patterns seen in our study seem to suggest that it is absolutely necessary to obtain sensitivity reports before initiation of antibiotic therapy in cases of suspected UTIs (Table 3 ). 
Table.1 Frequency distribution of age, gravidity and parity with ESBL and Non-ESBL isolates from patients

\begin{tabular}{|c|c|c|c|c|c|}
\hline Variable & Sub-category & $\begin{array}{c}\text { Number of } \\
\text { isolates from } \\
\text { patients }\end{array}$ & $\begin{array}{l}\text { ESBL isolates } \\
\text { from patients } \\
(n=8)\end{array}$ & $\begin{array}{c}\text { Non-ESBL } \\
\text { isolates from } \\
\text { patients }(n=44)\end{array}$ & p-value \\
\hline \multirow[t]{7}{*}{ Age } & $<20$ & $11(6.51)$ & $1(9.09)$ & $5(45.45)$ & \multirow[t]{7}{*}{0.545} \\
\hline & $20-25$ & $81(47.93)$ & $4(4.94)$ & $19(23.46)$ & \\
\hline & $25-30$ & $56(33.14)$ & $3(5.36)$ & $14(25)$ & \\
\hline & 30-35 & $16(9.47)$ & 0 & $5(31.25)$ & \\
\hline & $35-40$ & $5(2.96)$ & 0 & $1(20)$ & \\
\hline & Mean \pm SD & $24.69 \pm 4.15$ & $23.62 \pm 3.16$ & $24.57 \pm 4.15$ & \\
\hline & Age Range & $(18,40)$ & $(18,28)$ & $(18,35)$ & \\
\hline \multirow[t]{2}{*}{ Gravidity } & primigravida & $71(42.01)$ & $5(2.96)$ & $13(7.69)$ & \multirow[t]{2}{*}{0.1034} \\
\hline & multigravida & $98(57.99)$ & $3(1.78)$ & $31(18.34)$ & \\
\hline \multirow[t]{2}{*}{ Parity } & primiparous & $79(46.75)$ & $5(2.96)$ & $16(9.47)$ & \multirow[t]{2}{*}{0.2634} \\
\hline & multiparous & $90(53.25)$ & $3(1.78)$ & $28(16.57)$ & \\
\hline \multicolumn{2}{|c|}{ Gestational Age (in days) } & $210.22 \pm 58.4$ & $164.62 \pm 67.6$ & $207.86 \pm 61.56$ & 0.07764 \\
\hline
\end{tabular}

Table.2 ESBL producers among Gram negative bacteria

\begin{tabular}{|c|c|c|c|}
\hline Isolates & $\begin{array}{c}\text { ESBL } \\
\text { Producers (\%) }\end{array}$ & $\begin{array}{c}\text { Non-ESBL Producers } \\
(\boldsymbol{\%})\end{array}$ & Total (\%) \\
\hline Escherichia coli & $3(9.68)$ & $28(90.32)$ & $31(59.61)$ \\
\hline Citrobacter freundii & $2(50)$ & $2(50)$ & $4(7.69)$ \\
\hline Klebsiella pneumoniae & $1(12.5)$ & $10(90.9)$ & $11(17.31)$ \\
\hline Citrobacter koseri & $1(50)$ & $1(50)$ & $2(3.84)$ \\
\hline Proteus mirabilis & $1(20)$ & $4(80)$ & $5(9.62)$ \\
\hline Proteus vulgaris & $\mathrm{O}(0)$ & $1(100)$ & $1(1.92)$ \\
\hline Total & $8(15.38)$ & $46(85.18)$ & $54(100)$ \\
\hline
\end{tabular}

Table.3 Antibiotic resistance profile of ESBL bacterial isolates

\begin{tabular}{|c|c|c|c|c|c|c|}
\hline Antibiotics & $\begin{array}{c}\text { Escherichia } \\
\text { coli } \\
(\mathbf{n = 3})\end{array}$ & $\begin{array}{c}\text { Citrobacter } \\
\text { freundii } \\
(\mathbf{n = 2})\end{array}$ & $\begin{array}{c}\text { Citrobacter koseri } \\
(\mathbf{n = 1})\end{array}$ & $\begin{array}{c}\text { Klebsiella } \\
\text { pneumoniae } \\
(\mathbf{n = 1})\end{array}$ & $\begin{array}{c}\text { Proteus } \\
\text { mirabilis } \\
(\mathbf{n}=\mathbf{1})\end{array}$ & $\begin{array}{c}\text { Total } \\
(\mathbf{\%})\end{array}$ \\
\hline MRP & 0 & 0 & 0 & 0 & $1(100)$ & $1(12.5)$ \\
\hline COT & $2(66.67)$ & $1(50.00)$ & 0 & $1(100)$ & $1(100)$ & $5(62.5)$ \\
\hline CXM & $2(66.67)$ & $1(50 \%)$ & $1(100 \%)$ & 0 & $1(100)$ & $5(62.5)$ \\
\hline AMP & $2(66.67)$ & $1(50.00)$ & 0 & 0 & 0 & $3(37.5)$ \\
\hline GEN & $1(33.33)$ & 0 & $1(100.00)$ & 0 & $1(100)$ & $3(37.5)$ \\
\hline NX & $3(100)$ & 0 & 0 & 0 & $1(100)$ & $4(50)$ \\
\hline CAZ & $2(66.67)$ & $2(100)$ & $1(100.00)$ & $1(100)$ & $1(100)$ & $7(77.78)$ \\
\hline AMC & $3(100)$ & $1(50.00)$ & 0 & 0 & 0 & $4(50)$ \\
\hline PTZ & $1(33.33)$ & 0 & $1(100.00)$ & $1(100)$ & $1(100)$ & $4(50)$ \\
\hline IMP & $1(33.33)$ & 0 & $1(100.00)$ & 0 & 0 & $2(25)$ \\
\hline NIT & $1(33.33)$ & $2(100)$ & 0 & $1(100)$ & 0 & $4(50)$ \\
\hline
\end{tabular}

Abbreviations: - AMP:-Ampicillin, AMC:-amoxicillin-clavulanic acid, COT: - cotrimoxazole, CXM:- Cefuroxime, GEN:- gentamicin, NX :- Norfloxacin, CAZ:- Ceftazidime, PTZ:- Piperacillin-tazobactam, IMP:- Imipenem, NIT:Nitrofurantoin, 
The study emphasizes that microbiology laboratories should adequately screen for ESBL-producing strains of the family Enterobacteriaceae as the infections caused by these organisms are difficult to treat. Limitation of this study is, only the symptomatic pregnant women were included in the study, further studies should be done to include both symptomatic and asymptomatic pregnant women with UTI over a longer period of time to get proper trend of antibiotic resistance in the hospital.

ESBL producing organisms are increasing rapidly and are a major problem among the pregnant women all over the world. This study showed that pregnant women harbour one or more urinary pathogens that are antibiotic resistant. So the routine urine culture test for pregnant women is mandatory. Further the pregnant women should be educated to maintain hygiene in pregnancy. Therefore it is also suggested that further investigations to be undertaken to study the microbiological factors that make ESBL producing bacteria.

\section{References}

Bajpai T, Pandey M, Varma M, Bhatambare G. Prevalence of extended spectrum beta- lactamase producing uropathogens and their antibiotic resistance profile in patients visiting a tertiary care hospital in central India: Implications on empiric therapy Indian Journal of Pathology and Microbiology. 2014; 57(3): 407-12.

Bauer AW, Kirby WM, Sherris JC, Turck M. Antibiotic susceptibility testing by a standardized single disk method. Am J ClinPathol 1966; 45: 493-6.

Christensen B. Use of antibiotics to treat bacteriuria of pregnancy in the Nordic countries. Which antibiotics are appropriate to treat bacteriuria of pregnancy? Int J Antimicrob Agents. 2001; 17: 283-285.

Clinical Laboratory Standards Institute. Performance Standard for Antimicrobial Susceptibility Testing. 23rd Information Supplement. CLSI Document M100-S27. Wayne, PA, USA, 2017.

Collee JG, Fraser AG, Marmian BP, Simmons A, editors. Mackie and McCartney Practical Medical Microbiology. 14th ed. Standard ed. Churchill Livingstone, London,1996. (Reprinted 1999).

Durmaz R, Durmaz B, Koroglu M, Tekerekoglu MS (2001) Detection and typing of extended - spectrum $\beta$ lactamases in clinical isolates of the family enterobacteriaceae in a medical center in Turkey. Microb Drug Resist 7: 171-175.

Kuzucu C, Yetkin F, Ersoy Y. Investigation of the susceptibities of extended spectrum beta lactamase producing $E$ coli and Klebsiella spp. strains to ertapenem and other carbapenems. Mikrobiyol Bul. 2011; 45: 28-35.

Mohammed I, Abass E. Phenotypic detection of Extended Spectrum $\beta$-Lactamases (ESBL) among gram negative uropathogens reveals highly susceptibility to imipenem. Pak J Med Sci. 2019;35(4):1104-1109.

Muharram SH, Ghazali SNB, Yaakub HR, Abiola O. A Preliminary Assessment of Asymptomatic Bacteriuria of Pregnancy in Brunei Darussalam. Malays J Med Sci. 2014; 21: 34-39.

Mukherjee M, Basu S, Mukherjee SK, Majumder M. Multidrug-resistance and extended spectrum betalactamase production in uropathogenic E. coli which were isolated from hospitalized patients in Kolkata, India. J Clin Diagn Res. 2013; 7: 449-53.

Naiemi NA, Murk JL, Savelkoul PH, Vandenbroucke-Grauls CM, Debets- 
Ossenkopp YJ. Extended-spectrum beta-lactamases screening agar with AmpC inhibition. Eur J Clin Microbiol Infect Dis 2009; 28: 989-90.
Wilson ML, Gaido L. Laboratory diagnosis of urinary tract infections in adult patients. Clin Infect Dis. 2004; 38(8): $1150-1158$.

\section{How to cite this article:}

Sudhir Joshilkar and Madhumati Patil. 2019. Prevalence of Extended Spectrum of Beta Lactamase (ESBL) Producing Uropathogens from Pregnant Women in a Tertiary Care Hospital. Int.J.Curr.Microbiol.App.Sci. 8(11): 801-806. doi: https://doi.org/10.20546/ijcmas.2019.811.094 